\title{
UPAYA ORANG TUA DALAM PEMBENTUKAN KARAKTER KEBANGSAAN ANAK USIA DINI MELALUI CARA MEMILIH PRODUK
}

\author{
Anang Priyanto ${ }^{1}$, Pratiwi Wahyu Widiarti², Lies Endarwati ${ }^{3}$ \\ ${ }^{1}$ Fakulltas Ilmu Sosial Universitas Negeri Yogyakarta \\ ${ }^{2}$ Fakulltas Ilmu Sosial Universitas Negeri Yogyakarta \\ ${ }^{3}$ Fakulltas Ekonomi, Universitas Negeri Yogyakarta \\ email: anang_priyanto@uny.ac.id
}

\begin{abstract}
The purpose of this research is to find out parent efforts to build young children character, parent behavior to choose daily needs and to develop model of character building by selection of products on young children. This is a survei and mixed method model. The results of this study were (1) Parent skill in choosing Indonesian product are poor $25.1 \%$, fail or medium $53.9 \%$, and good $21 \%$ product selectivity. The most committed effort by parent to make their children love Indonesia product. The second place is by introducing Indonesian product to their children by using and wearing Indonesian product. Parent is easier Indonesian product by seeing the brand. Parent find it is difficult to identify Indonesian product in the global era.
\end{abstract}

Keywords: character building, young children, Indonesian product

\section{PENDAHULUAN}

Peran keluarga sangat penting dan mendasar untuk membentuk karakter seseorang dan sekarang ini mulai diabaikan karena dianggap sebagai peran informal. Saat bayi dilahirkan lingkungan yang dikenal pertama kali dan tempat dia mengenal segala sesuatu adalah keluarga. Pendampingan keluarga kepada anak sejak usia dini merupakan pendidikan informal yang sangat penting dalam menanamkan nilai-nilai kebangsaan yang akan mengantarkan Bangsa dan Negara menuju masa depan yang gemilang.

Keberlanjutan dan keberhasilan masa depan Bangsa dan Negara Indonesia, sangat tergantung pada karakter anak-anak yang sekarang masih berusia dini. Kecintaan akan Bangsa dan Negara perlu ditanamkan sejak usia dini. Penanaman cinta Bangsa dan Negara menjadi peran penting bagi keluarga khususnya orang tua, sehingga terbentuk karakter kebangsaan yang kuat. Banyak cara yang dapat dilakukan orang tua untuk menanamkan nilai karakter kebangsaan kepada anak, antara lain pengenalan lagu kebangsaan, bendera Indonesia, penggunaan Bahasa Indonesia yang baik dan benar, cerita kepahlawanan Indonesia, kekayaan alam Indonesia, kekayaan seni Indonesia, kekayaan budaya Indonesia, pemilihan produk 
Indonesia dan lain-lain. Pemilihan produk Indonesia menjadikan kita menghargai hasil karya bangsa sendiri. Namun tidak mudah untuk menjadikan cinta pada produk bangsa sendiri. Di samping produk harus lebih berkualitas ketimbang produk asing, namun juga rasa bangga menggunakan produk bangsa sendiri haruslah menjadi keutamaan dalam kebiasaan hidup bangsa ini. Untuk itulah kebangsaan terhadap produk bangsa Indonesia dapat dimulai dari produk makanan sehari-hari yang dimiliki bangsa Indonesia.

Masuknya era pasar bebas ASEAN tahun 2015 atau yang sering disebut dengan AFTA (ASEAN Free Trade Area) bangsa Indonesia mau tidak mau harus sudah siap menghadapi adanya persaingan bebas. Potensi Indonesia yang paling mudah diunggulkan dalam persaingan bebas tidak lain adalah soal produk makanan khas Indonesia. Produk makanan khas Indonesia paling mudah dibanggakan dan unggul dalam persaingan dengan catatan produknya harus berkualitas, higienis dan terjangkau. Amatlah disayangkan jika anak-anak muda bangsa ini lebih bangga terhadap produk asing ketimbang produk bangsa sendiri. Hasil penelitian mahasiswa Universitas Sanata Dharma Yogyakarta (Natas, edisi Maret 2014) membuktikan hal tersebut. Dalam penelitian tersebut ditunjukkan bahwa $15 \%$ Starbuck menjadi top brand anak remaja untuk tempat nongkrong, 22,1\% Levi's menjadi celana jeans nomor satu di kalangan remaja Indonesia, dan 16,7\% sepatu sekolah terkenal bagi remaja adalah Converse.

Sangatlah memprihatinkan seandainya para generasi muda bangsa ini lebih merasa bangga menggunakan dan mengonsumsi produk asing ketimbang produk bangsa sendiri. Hal ini tidak boleh dibiarkan, harus ada upaya untuk menghidupkan rasa bangga kepada produk bangsa sendiri. Kebanggaan terhadap produk bangsa sendiri menunjukkan kuatnya wujud karakter kebangsaan. Upaya yang paling utama dapat dilakukan adalah melalui keluarga yang ditanamkan kepada anak sejak usia dini. Keluarga merupakan komunitas terkecil yang memiliki peran utama dalam pembentukan karakter anak bangsa ini. Dari keluarga lah seorang anak yang lahir di dunia ini mulai pertama kali mengenal kehidupan yang dapat mewarnai karakternya. Melalui keluarga peran orang tua sangat penting dalam menanamkan nilai kebangsaan pada anak-anak sejak usia dini, salah satu yang dapat dilakukan dengan cara mengkonsumsi/memilih barang produk Indonesia. Di samping sebagai 
upaya untuk membentuk karakter kebangsaan kepada anak juga dapat merupakan salah satu upaya untuk menghambat banjirnya barang impor di wilayah Indonesia. Demikian pula dapat memfasilitasi tumbuhnya produksi dalam negeri yang selanjutnya akan meningkatkan ketahanan ekonomi bangsa Indonesia.

Sejak usia dini kepada bangsa Indonesia harus ditanamkan nilai untuk mencintai dan mengkonsumsi produk Indonesia. Mencintai dan mengonsumsi produk Indonesia menjadikan nilai kebangsaan dapat meresap dalam diri setiap bangsa Indonesia yang pada akhirnya akan menjadi karakter bangsa. Nilai kebangsaan yang ditunjukkan melalui cara memilih produk (cinta produk Indonesia) akan menciptakan ketahanan nasional terutama melalui ketahanan ekonomi. Dengan adanya pasar bebas ASEAN yang dikenal dengan sebutan AFTA pada tahun 2015, dan pasar bebas Asia-Pasifik pada tahun 2020, ketahanan produk Indonesia sangat terancam. Pembentukan karakter kebangsaan pada anak usia dini melalui orang tua dalam keluarga sebagai salah satu solusi memperkuat ketahanan produk Indonesia di era AFTA.

Peran orang tua dalam keluarga amat penting dalam pembentukan karakter kebangsaan pada anak sejak usia dini walaupun dikatakan merupakan jalur pendidikan non formal. Samsuri (2011) menuliskan bahwa pendidikan karakter secara masif di jalur pendidikan formal tidak menjamin keberhasilan tujuan nasional pembentukan karakter ideal warga negara. Gerakan masif pendidikan karakter bisa berhasil jika didukung oleh kesadaran dan partisipasi lingkungan keluarga, masyarakat sekitar, lingkungan sekolah, dan pemimpin di masing-masing tingkatan untuk mewujudkannya dalam kehidupan sehari-hari.

Dari latar belakang masalah tersebut, maka dapat dirumuskan permasalahan berikut ini:

1. Apa upaya yang dilakukan orang tua dalam membentuk karakter kebangsaan pada anak usia dini?

2. Bagaimana orang tua dari anak usia dini memberikan pembelajaran pada anak dalam memilih produk untuk memenuhi kebutuhan sehari-hari?

\section{METODE PENELITIAN}

Penelitian ini merupakan penelitian deskriptif dengan pendekatan kuantitatif dan kualitatif. Pendekatan kuantitatif merupakan semua informasi atau data yang 
diwujudkan dalam bentuk angka dan dianalisis berdasarkan angka dengan menggunakan analisis statistik deskriptif. Disamping itu juga dilakukan dengan pendekatan kualitatif sebagai rancangan bantu agar penelitian dapat mendeskripsikan objek secara lengkap dan mendalam. Jadi pendekatan penelitian ini menggunakan metode mixed method.

Populasi penelitian ini adalah keluarga yang mempunyai anak usia dini (usia anak sampai dengan 6 tahun) yang tinggal di wilayah Daerah Istimewa Yogyakarta dengan sampel penelitian ditentukan secara multystage sampling, yakni dengan menentukan sampel area secara probabilita (area probilita sampling) kemudian secara acak ditentukan jumlah keluarga yang menjadi responden yang diambil secara proporsional setiap wilayah (proporsional random sampling) lalu responden ditentukan secara berkelompok dilihat dari tingkat penghasilan keluarga (stratified sampling) dan setiap kelompok ditentukan secara purposive sampling terlebih dahulu.

Jumlah responden dalam penelitian ini 458 orang, dengan rincian per kabupaten/kota sebagai berikut:
1. Kabupaten Sleman
: 75 orang
2. Kota Yogyakarta
: 116 orang
3. Kabupaten Bantul
: 72 orang
4. Kabupaten Kulonprogo : 97 orang
5. Kabupaten Gunungkidul : 98 orang.

\section{HASIL DAN PEMBAHASAN}

\section{Karakteristik Subjek Penelitian}

Usia subjek terbanyak adalah usia 35 tahun, 40 orang $(8,7 \%)$. Sedangkan yang tidak mengisi kolom usia ada sebanyak 49 orang (10,7\%). Jenis kelamin lakilaki ada 87 orang (19\%) dan jenis kelamin perempuan ada 348 orang (76\%), sedangkan untuk jenis kelamin yang tidak diisi ada 23 orang (5\%). Jadi yang terbanyak adalah orang tua berjenis kelamin perempuan sebanyak 348 (76\%) dari 458 orang tua.

Pendidikan subjek terbanyak adalah tingkat SMA sebanyak 230 orang tua (50,2\%). Pekerjaan subjek terbanyak adalah sebagai Ibu Rumah Tangga sebanyak 208 orang tua $(45,4 \%)$. Pendidikan pasangan terbanyak adalah tingkat SMA 
sebanyak 202 orang tua (44,1\%). Pekerjaan suami/istri terbanyak adalah pegawai swasta sebanyak 142 orang $(31,0 \%)$.

Jumlah anak terbanyak adalah 2 anak ada 194 orang $(42,4 \%)$ dalam satu keluarga. Jumlah anak usia dini rata-rata yang dimiliki keluarga adalah 1 anak $(69,7 \%)$.

Penghasilan rata-rata orang tua adalah sebesar Rp. 601.000- Rp.1.000.000 $(26,9 \%)$. Kepandaian orang tua dalam memilih produk Indonesia ada 115 orang $(25,1 \%)$ kurang baik, 247 orang $(53,9 \%)$ tingkat kepandaiannya sedang, dan 96 orang $(21,0 \%)$ tingkat kepandaian memilih produk baik. Dari hasil ini menunjukkan bahwa sebagian besar $(53,9 \%)$ kepandaian orang tua dalam memilih produk Indonesia masih masuk kategori sedang. Hal ini mengindikasikan perlunya upaya untuk meningkatkan kepandaian orang tua dalam memilih produk Indonesia.

\section{Tabulasi Silang Identitas Dengan Pemilihan Produk Secara Menyeluruh}

\section{Tabulasi Silang Umur dengan Pemilihan Produk di DIY}

Tabel Tabulasi Silang Umur dengan Pemilihan Produk di DIY

\begin{tabular}{|c|c|c|l|}
\hline \multicolumn{4}{|c|}{ Symmetric Measures } \\
\hline \multicolumn{2}{|c|}{} & Value & $\begin{array}{l}\text { Approx. } \\
\text { Sig. }\end{array}$ \\
\hline $\begin{array}{c}\text { Nominal by } \\
\text { Nominal }\end{array}$ & $\begin{array}{c}\text { Contingency } \\
\text { Coefficient }\end{array}$ &, 394 &, 045 \\
\hline \multicolumn{2}{|c|}{ Nof Valid Cases } & 458 & \\
\hline
\end{tabular}

Sumber: Data diolah peneliti, 2016.

Dari tabel di atas dapat disimpulkan bahwa umur berkaitan dengan pemilihan produk, hal ini tampak dalam angka C (Koefisien Kontingensi) sebesar 0,394 dengan tingkat signifikansi 0,045(<0,05). Dari hasil ini menunjukkan bahwa usia orang tuaakan menentukan tingkat kepandaian memilih produk Indonesia.

\section{Tabulasi Silang Jenis Kelamin dengan Pemilihan Produk di DIY}

Tabel Tabulasi Silang Jenis Kelamin dengan Pemilihan Produk di DIY

\begin{tabular}{|c|c|c|c|}
\hline \multicolumn{4}{|c|}{ Symmetric Measures } \\
\hline & & Value & $\begin{array}{l}\text { Approx. } \\
\text { Sig. }\end{array}$ \\
\hline Nominal by Nominal & $\begin{array}{c}\text { Contingency } \\
\text { Coefficient }\end{array}$ & ,042 & 937 \\
\hline \multicolumn{2}{|c|}{$N$ of Valid Cases } & 458 & \\
\hline
\end{tabular}

Sumber: Data diolah peneliti, 2016. 
Dari tabel di atas dapat disimpulkan bahwa jenis kelamin tidak berkaitan dengan pemilihan produk, karena nilai signifikansinya 0,937 $(>0,05)$. Dari hasil ini menunjukkan bahwa orang tua baik Ayah atau Ibu tidak beda tingkat kepandaiannya dalam memilih produk Indonesia.

\section{Tabulasi Silang Tingkat Pendidikan dengan Pemilihan Produk di DIY}

Tabel Tabulasi Silang Tingkat Pendidikan dengan Pemilihan Produk di DIY

\begin{tabular}{|c|c|c|c|}
\hline \multicolumn{4}{|c|}{ Symmetric Measures } \\
\hline & & Value & $\begin{array}{l}\text { Approx. } \\
\text { Sig. }\end{array}$ \\
\hline Nominal by Nominal & $\begin{array}{l}\text { Contingency } \\
\text { Coefficient }\end{array}$ & ,238 &, 006 \\
\hline Nof Valid Cases & & 458 & \\
\hline
\end{tabular}

Sumber: Data diolah peneliti, 2016.

Dari tabel di atas dapat disimpulkan bahwa pendidikan subjek berkaitan dengan pemilihan produk, hal ini tampak dalam angka $\mathrm{C}$ (Koefisien Kontingensi) sebesar 0,238 (sign 0,006). Hasil ini menunjukkan tingkat kepandaian orang tua dalam memilih produk Indonesia ditentukan juga oleh tingkat pendidikannya.

\section{Tabulasi Silang Jenis Pekerjaan dengan Pemilihan Produk di DIY}

Tabel Tabulasi Silang Jenis Pekerjaan dengan Pemilihan Produk di DIY

\begin{tabular}{|l|l|l|l|}
\hline \multicolumn{3}{|c|}{ Symmetric Measures } \\
\hline \multicolumn{2}{|c|}{} & Value & $\begin{array}{l}\text { Approx. } \\
\text { Sig. }\end{array}$ \\
\hline Nominal by Nominal & $\begin{array}{l}\text { Contingency } \\
\text { Coefficient }\end{array}$ &, 166 &, 224 \\
\hline N of Valid Cases & 458 & \\
\hline
\end{tabular}

Sumber: Data diolah peneliti, 2016.

Dari tabel di atas dapat disimpulkan bahwa pekerjaan subjek tidak berkaitan dengan pemilihan produk, karena nilai signifikansi 0,224 $(>0,05)$. Hal ini menunjukkan bahwa jenis pekerjaan orang tua tidak menentukan tingkat kepandaian dalam memilih produk Indonesia. 


\section{Tabulasi Silang Jenis Pendidikan Pasangan dengan Pemilihan Produk di} DIY

Tabel Tabulasi Silang Jenis Pendidikan Pasangan dengan Pemilihan Produk di DIY

\begin{tabular}{|l|l|l|l|}
\hline \multicolumn{4}{|c|}{ Symmetric Measures } \\
\hline Nominal by Nominal & $\begin{array}{l}\text { Contingency } \\
\text { Coefficient }\end{array}$ &, 225 &, 018 \\
\hline Nof Valid Cases & 458 & \\
\hline
\end{tabular}

Sumber: Data diolah peneliti, 2016.

Dari tabel di atas dapat disimpulkan bahwa pendidikan pasangan subjek berkaitan dengan pemilihan produk, hal ini tampak dalam angka $\mathrm{C}$ (Koefisien Kontingensi) sebesar 0,225 (sign 0,018). Hasil ini menunjukkan bahwa tingkat pendidikan pasangan (suami/istri) menentukan kepandaian orang tua(suami/istri) dalam memilih produk Indonesia.

\section{Tabulasi Silang Jenis Pekerjaan Pasangan dengan Pemilihan Produk di}

\section{DIY}

Tabel Tabulasi Silang Jenis Pekerjaan Pasangan dengan Pemilihan Produk di DIY

\begin{tabular}{|l|l|l|l|}
\hline \multicolumn{2}{|l|}{ Symmetric Measures } & Value & $\begin{array}{l}\text { Approx. } \\
\text { Sig. }\end{array}$ \\
\hline Nominal by Nominal & $\begin{array}{l}\text { Contingency } \\
\text { Coefficient }\end{array}$ &, 229 &, 013 \\
\hline N of Valid Cases & 458 & \\
\hline
\end{tabular}

Sumber: Data diolah peneliti, 2016.

Dari tabel di atas dapat disimpulkan bahwa pekerjaan pasangan subyek berkaitan dengan pemilihan produk, hal ini tampak dalam angka C (Koefisien Kontingensi) sebesar 0,229 (sign 0,013). Hasil ini menunjukkan bahwa pekerjaan pasangan (suami/istri) menentukan kepandaian orang tua(suami/istri) dalam memilih produk Indonesia.

\section{Tabulasi Silang Jumlah Anak dengan Pemilihan Produk di DIY}

Tabel Tabulasi Silang Jumlah Anak dengan Pemilihan Produk di DIY

\begin{tabular}{|l|l|l|l|}
\hline \multicolumn{4}{|c|}{ Symmetric Measures } \\
\hline \multicolumn{2}{|l|}{} & Value & Approx. Sig. \\
\hline Nominal by Nominal & $\begin{array}{l}\text { Contingency } \\
\text { Coefficient }\end{array}$ &, 205 &, 065 \\
\hline N of Valid Cases & 458 & \\
\hline
\end{tabular}

Sumber: Data diolah peneliti, 2016. 
Dari tabel di atas dapat disimpulkan bahwa jumlah anak tidak berkaitan dengan pemilihan produk, karena nilai signifikansi 0,65 (>0,05). Hasil ini menunjukkan bahwa jumlah anak tidak menentukan kepandaian orang tua dalam memilih produk Indonesia.

\section{Tabulasi Silang Jumlah Anak Usia Dini dengan Pemilihan Produk di DIY}

Tabel Tabulasi Silang Jumlah Anak Usia Dini dengan Pemilihan Produk di DIY

\begin{tabular}{|l|l|l|l|}
\hline \multicolumn{2}{|l|}{ Symmetric Measures } & Value & Approx. Sig. \\
\hline Nominal by Nominal & $\begin{array}{l}\text { Contingency } \\
\text { Coefficient }\end{array}$ &, 179 &, 231 \\
\hline N of Valid Cases & 458 & \\
\hline
\end{tabular}

Sumber: Data diolah peneliti, 2016.

Dari tabel di atas dapat disimpulkan bahwa jumlah anak usia dini tidak berkaitan dengan pemilihan produk di DIY. Hasil ini menunjukkan bahwa jumlah anak usia dini tidak menentukan kepandaian orang tua dalam memilih produk Indonesia.

\section{Tabulasi Silang Penghasilan dengan Pemilihan Produk di DIY}

Tabel Tabulasi Silang Penghasilan dengan Pemilihan Produk di DIY

\begin{tabular}{|l|l|l|l|}
\hline \multicolumn{2}{|l|}{ Symmetric Measures } & Value & $\begin{array}{l}\text { Approx. } \\
\text { Sig. }\end{array}$ \\
\hline Nominal by Nominal & $\begin{array}{l}\text { Contingency } \\
\text { Coefficient }\end{array}$ &, 259 &, 001 \\
\hline Nof Valid Cases & 458 & 458 \\
\hline
\end{tabular}

Sumber: Data diolah peneliti, 2016.

Dari tabel di atas dapat disimpulkan bahwa penghasilan berkaitan dengan pemilihan produk hal ini tampak dalam angka C (Koefisien Kontingensi) sebesar 0,259 (sign 0,001). Hasil ini menunjukkan bahwa penghasilan menentukan kepandaian orang tua dalam memilih produk Indonesia. 
10. Rangkuman Hasil Tabulasi Silang Pemilihan Produk dengan

\section{Karakteristik Orang tua}

Tabel Tabulasi Silang Pemilihan

Produk Karakteristik Orang Tua

\begin{tabular}{|l|l|c|c|l|}
\hline No. & \multicolumn{1}{|c|}{ Indikator } & C & Sign & Kesimpulan \\
\hline 1. & Umur & 0,394 & 0,045 & Berkaitan \\
\hline 2. & Jenis kelamin & 0,042 & 0,937 & Tidak berkaitan \\
\hline 3. & Pendidikan subyek & 0,238 & 0,006 & Berkaitan \\
\hline 4. & Pekerjaan subyek & 0,166 & 0,224 & Tidak berkaitan \\
\hline 5. & Pendidikan pasangan & 0,225 & 0,018 & Berkaitan \\
\hline 6. & Pekerjaan pasangan & 0,229 & 0,013 & Berkaitan \\
\hline 7. & Jumlah anak & 0,205 & 0,065 & Tidak berkaitan \\
\hline 8. & Jumlah anak usia dini & 0,179 & 0,231 & Tidak berkaitan \\
\hline 9. & Penghasilan & 0,259 & 0,001 & Berkaitan \\
\hline
\end{tabular}

Sumber: Data diolah peneliti, 2016.

Dari tabel di atas dapat disimpulkan bahwa faktor karakteristik orang tua yang menentukan perilaku orang tua anak usia dini untuk memberikan pembelajaran pada anak dalam memilih produk untuk kebutuhan sehari-hari adalah umur, pendidikan, pendidikan pasangan, pekerjaan pasangan, dan penghasilan.

\section{Hasil Kualitatif Angket Terbuka}

1. Upaya Yang Dilakukan Orang Tua Kepada Putra/Putrinya Untuk Mencintai Produk Indonesia

Tabel Upaya Orang Tua Kepada Anak

Untuk Mencintai Produk Indonesia

\begin{tabular}{|l|l|l|}
\hline No & \multicolumn{1}{|c|}{ Upaya Orang tua } & \multicolumn{1}{|c|}{ Persentase (\%) } \\
\hline 1 & mengenalkan budaya Indonesia & 55,07 \\
\hline 2 & mengenalkan produk Indonesia & 27,54 \\
\hline 3 & $\begin{array}{l}\text { mengenalkan kekayaan alam, daerah } \\
\text { Indonesia }\end{array}$ & 13,04 \\
\hline 4 & mengenalkan keragaman Indonesia & 4,35 \\
\hline 5 & mengajarkan tentang Indonesia & 2,9 \\
\hline
\end{tabular}

Sumber: Data diolah peneliti, 2016. 
Dari tabel di atas dapat disimpulkan bahwa upaya orang tua kepada anak untuk mencintai produk Indonesia paling banyak dilakukan dengan mengenalkan budaya Indonesia $(55,07 \%)$. Dari hasil ini menunjukkan upaya yang paling banyak dilakukan orang tua kepada anak untuk mencintai produk Indonesia dengan cara mengenalkan budaya Indonesia.

\section{Upaya Yang Subjek Lakukan Untuk Mengenalkan Produk Indonesia (Makanan, Minuman, Barang Hasil Pabrik, Dll.) Kepada Putra/Putrinya \\ Tabel Upaya Orang Tua Untuk Mengenalkan Kepada Anak Produk Indonesia

\begin{tabular}{|l|l|l|}
\hline \multicolumn{1}{|c|}{ No } & \multicolumn{1}{|c|}{ Upaya Orang Tua } & \multicolumn{1}{c|}{ Persentase (\%) } \\
\hline 1 & Menggunakan produk Indonesia & 68,12 \\
\hline 2 & $\begin{array}{l}\text { Membiasakan mengonsumsi } \\
\text { masakan sendiri }\end{array}$ & 14,50 \\
\hline 3 & Membaca label barang & 10,14 \\
\hline 4 & Mengajak ke pasar tradisional & 7,24 \\
\hline
\end{tabular}

Sumber: Data diolah peneliti, 2016.

Dari tabel di atas dapat disimpulkan bahwa upaya orang tua mengenalkan kepada anak produk Indonesia paling banyak dilakukan dengan menggunakan atau memakai produk Indonesia $(68,12 \%)$. Dari hasil ini menunjukkan upaya paling banyak dilakukan orang tua untuk mengenalkan kepada anak produk Indonesia dengan cara menggunakan atau memakai produk Indonesia.

\section{Orang tua merasa mudah mengenali produk Indonesia.}

Dari pertanyaan terbuka ini ada 71,01\% menjawab "Ya", 21,73\% menjawab "Tidak" dan ada 7,24\% tidak memberikan jawaban.

a. Menjawab "Ya" sebanyak $71,01 \%$ dengan alasan:

Tabel Orang Tua Mudah Mengenali Produk Indonesia

\begin{tabular}{|c|l|l|}
\hline No & \multicolumn{1}{|c|}{ Upaya Orang Tua } & Persentase \\
\hline 1 & Dengan melihat mereknya & 34,69 \\
\hline 2 & Melihat label produknya & 28,57 \\
\hline 3 & Melihat ciri khas produk & 14,28 \\
\hline 4 & Membiasakan mengomentari produk lokal & 12,24 \\
\hline 5 & Melihat kemasan & 10,20 \\
\hline
\end{tabular}

Sumber: Data diolah peneliti, 2016. 
Dari tabel di atas dapat disimpulkan bahwa orang tua mudah dalam mengenali produk Indonesia dengan cara melihat mereknya (34,69\%). Dari hasil ini menunjukkan orang tua mengenali produk Indonesia dengan mudah dengan cara melihat mereknya.

b. Menjawab "Tidak" sebanyak 21,73\% dengan alasan:

Tabel Alasan Orang Tua

Tidak Mudah Mengenali Produk Indonesia

\begin{tabular}{|l|l|l|}
\hline No & \multicolumn{1}{|c|}{ Upaya Orang Tua } & $\begin{array}{c}\text { Persentase } \\
(\mathbf{\%})\end{array}$ \\
\hline 1 & Di era global sulit mencermati produk Indonesia & 26,60 \\
\hline 2 & Produk luar mirip dengan produk Indonesia & 20 \\
\hline 3 & Produk luar banyak yang beredar di Indonesia & 20 \\
\hline 4 & Produk Indonesia banyak yang meniru produk luar & 20 \\
\hline 5 & Merek Indonesia kurang familiar & 13,33 \\
\hline
\end{tabular}

Sumber: Data diolah peneliti, 2016.

Dari tabel di atas dapat disimpulkan bahwa alasan orang tua tidak mudah dalam mengenali produk Indonesia karena di era global sulit mencermati produk Indonesia (26,60\%). Dari hasil ini menunjukkan orang tua mengenali produk Indonesia tidak mudah karena di era global sangat sulit mencermati produk Indonesia.

\section{Hasil Focus Group Discussion(FGD):}

Hasil FGD diperoleh beberapa masukan yang berkait dengan peran orang tua dalam membentuk karakter kebangsaan anak melalui cara memilih produk Indonesia, antara lain:

a. Mencintai produk dalam negeri harus dimulai dari orang tua atau lingkungan keluarga, misalnya dengan cara berceritera, tentang produk yang dimiliki Indonesia, sehingga memerlukan panduan tentang cara untuk mengenali produk dalam negeri.

b. Pilihkan produk yang dapat mendekatkan relasi orang tua dengan anak melalui kegiatan. Perlu workshop membuat boneka tangan (cerita) dari kain flanel, playdough, dan media permainan lainnya, anak dilibatkan dalam membuat, dan orang tua bermain bersama anak. 
c. Buat cerita bergambar untuk mengenalkan produk asli Indonesia. Dalam kegiatan bermain, optimalkan penggunaan Alat Permainan Edukatif Tradisional (APET).

d. Ajak anak ke pasar dan kenalkan langsung si anak pada makanan organik atau menu sehat. Salah satu solusi agar anak tidak tergantung pada gadget, susun media audio visual yang menarik dan orang tuaharus mendampingi anak, sehingga interaksi orang tuadan anak tetap berlangsung dengan baik.

e. Membuat sendiri permainan dengan bahan-bahan yang berasal dari lingkungan setempat, misalnya gedebog pisang, kulit jeruk, bambu/carang. Kegiatan bermain anak: Anak lebih mudah diarahkan mengikuti permainan tradisional anak: dakon, egrang, bathok. Biasakan membuat permainan dengan memanfaatkan kertas bekas dan bermain bersama-sama.

f. Orang tua harus pandai mengatur anak dan mengarahkan anak untuk tidak bermain yang belum masanya.

g. Orang tua harus telaten membuat makanan sendiri. Biasakan makan nasi dan syur untuk perkembangan anak. Karena pendidikan anak berawal dari bagaimana orang tua mengarahkan dan mendidik anak.

h. Kebiasaan mengkonsumsi makanan pada anak sebagai bekal sekolah. Produk makanan lokal sebagai bekal makanan anak, tidak dapat dipenuhi oleh sebagian besar orang tua. Makanan yang dibawakan anak di sekolah lebih banyak makanan cepat saji dan snack yang tidak sehat.

i. Karena adanya krisis kepercayaan pada orang tuadan lebih percaya pada guru maka perlu sinergitas kegiatan di rumah dan di sekolah.

\section{KESIMPULAN}

Berdasarkan paparan pembahasan di atas, dapat disimpulkan beberapa poin di bawah ini:

1. Usia subjek terbanyak adalah usia 35 tahun, 40 orang $(8,7 \%)$.

2. Jenis kelamin yang terbanyak adalah orang tua berjenis kelamin perempuan sebanyak $348(76 \%)$.

3. Pendidikan subjek terbanyak adalah pendidikan SMA sebanyak 230 orang tua $(50,2 \%)$. 
4. Pekerjaan subjek terbanyak adalah sebagai Ibu Rumah Tangga sebanyak 208 orang tua $(45,4 \%)$.

5. Pendidikan pasangan terbanyak adalah tingkat SMA sebanyak 202 orang tua $(44,1 \%)$.

6. Pekerjaan pasangan (suami/istri) terbanyak adalah pegawai swasta sebanyak 142 orang $(31,0 \%)$.

7. Jumlah anak terbanyak adalah 2 anak ada 194 orang $(42,4 \%)$ dalam satu keluarga.

8. Jumlah anak usia dini rata-rata yang dimiliki keluarga adalah 1 anak $(69,7 \%)$.

9. Penghasilan rata-rata orang tua adalah sebesar Rp. 601.000- Rp.1.000.000 $(26,9 \%)$.

10. Kepandaian orang tua dalam memilih produk Indonesia ada 115 orang $(25,1 \%)$ kurang baik, 247 orang $(53,9 \%)$ tingkat kepandaiannya sedang, dan 96 orang $(21,0 \%)$ tingkat kepandaian memilih produk baik.

11. Faktor-faktor yang menentukan kepandaian orang tua anak usia dini dalam memilih produk untuk kebutuhan anak usia dini dan kebutuhan sehari-hari: Umur (C=0,394; Sign=0,045); Pendidikan orang tua $(C=0,238$; Sign=0,006); Pendidikan pasangan $(\mathrm{C}=0,225$; Sign $=0,018)$; Pekerjaan pasangan $(\mathrm{C}=0,229$; Sign=0,013); dan Penghasilan $(\mathrm{C}=0,179 ;$ Sign=0,231).

12. Hasil analisis data kualitatif:

a. Upaya yang paling banyak dilakukan orang tua kepada anak untuk mencintai produk Indonesia dengan cara mengenalkan budaya Indonesia $(55,07 \%)$.

b. Upaya paling banyak dilakukan orang tua untuk mengenalkan kepada anak produk Indonesia dengan cara menggunakan atau memakai produk Indonesia $(68,12 \%)$.

c. Orang tua merasa mudah mengenali produk Indonesia dengan melihat mereknya $(34,69 \%)$.

d. Orang tua merasa tidak mudah mengenali produk Indonesia sulit mencermati produk Indonesia di era global (26,60\%). 


\section{DAFTAR PUSTAKA}

Arikunto, Suharsimi. (2013). Prosedur Penelitian Suatu Pendekatan Praktik. Jakarta: Rineka Cipta.

Azwar, Saifuddin. (2002). Sikap Manusia: Teori dan Pengukurannya. Yogyakarta: Purtaka Pelajar.

Badu, Ruslin (2011). Pengembangan Model Pelatihan Permainan Tradisional Edukatif Berbasis Potensi Lokal dalam Meningkatkan Kemampuan dan Keterampilan Orang tua Anak Usia Dini di PAUD Kota Gorontalo, Jurnal Penelitian dan Pendidikan, Volume 8, Nomor 1.

Creswell, John W. (2013). Research Design Pendekatan Kualitatif, Kuantitatif, dan Mixed. Edisi Ketiga. Yogyakarta: Pustaka Pelajar.

Koesoema, Doni (2009). Pendidikan Karakter di Zaman Keblinger. Jakarta: Grasindo.

Elmubarok, Zaim (2009). Membumikan Pendidikan Nilai, Mengumpulkan yang Terserak, Menyambung yang Terputus, dan Menyatukan yang Tercerai. Bandung: Alfabeta.

Kotler, Philip \& Keller, Kevin Lane. (2012) Manajemen Pemasaran Edisi 13. Jakarta: Erlangga.

Santrock, John W. (2012). Life-Span Development, Sixth Edition. New York: McGraw Hill.

Samsuri. (2011). Pendidikan Karakter Warga Negara. Yogyakarta: Diandra Pustaka Indonesia.

Semiun, Yustinus. (2006) Teori kepribadian \& Terapi Psikoanalitik Freud. Yogyakarta: Penerbit Kanisius.

Sugiyono. (2008). Metode Penelitian Kuantitatif, Kualitatif dan $R \& D$. Bandung: Alfabeta.

Suryabrata, Sumadi. (1990). Psikologi Pendidikan. Jakarta: Rajawali Pres. 